\title{
CONTROVERSY
}

\section{Where should paediatric surgery be performed?}

\author{
G S Arul, R D Spicer
}

"The aim of paediatric surgery is to set a standard, not to create a monopoly"Dennis Browne

In 1959 the Platt report made a number of recommendations about caring for children in hospital. ${ }^{1}$ The six main principles were identified as: child and family centred care, specially skilled staff, separate facilities, effective treatments, appropriate hospitalisation, and strategic commissioning. While everybody accepts that these principles remain fundamental to the provision of health care for children, interpreting them in today's NHS can be difficult. In particular the role of the specialist paediatric surgical centre, in the context of providing comprehensive national paediatric care, has never been formally defined.

In 1989 the National Confidential Enquiry into Perioperative Deaths (NCEPOD) reporting on perioperative deaths in childhood made three particularly relevant recommendations ${ }^{2}$ :

- Surgeons and anaesthetists should not undertake occasional paediatric practice

- Consultants who take the responsibility for the care of children (particularly in district general hospitals and in single surgical specialty hospitals) must keep up to date and competent in the management of children

- Consultant supervision of trainees needs to be kept under scrutiny. No trainee should undertake any anaesthetic or surgical operation on a child of any age without consultation with their consultant.

Numerous paediatric surgical specialties are provided at district, regional, and supraregional level. These arrangements have often arisen on an ad hoc basis. In this report we review the literature on the way in which paediatric surgical care is provided throughout a region and how the service should ideally be organised. In particular we wish to define the distinction between specialist and general paediatric surgical care.

Department of

Paediatric Surgery, Bristol Royal Hospital for Sick Children, St Michael's Hill, Bristol BS2 8BJ, UK

G S Arul R D Spicer

Correspondence to: Mr Arul Reprint requests to: Mr Spicer.
- Neonatal surgery, which involves the care of infants up to 44 weeks postconceptional age

- Complex surgical conditions requiring special expertise such as oncology, hepatobil- iary disease, major trauma, and the reconstruction of congenital abnormalities

- Management of children with relatively straightforward surgical conditions who have associated disorders - for example, the child with an inguinal hernia who also has cardiac or respiratory disease and thus requires a more complicated anaesthetic

- Paediatric urology.

For a specialist surgical centre to provide appropriate care there needs not only to be paediatric surgery but also specialists in the fields of anaesthesia, oncology, radiology, intensive care, physiotherapy, and nursing.

\section{SURGERY}

There is little disagreement with the concept that all neonatal admissions should be dealt with in neonatal surgical centres. ${ }^{4-6}$ BAPS recommends that there should be one specialist paediatric surgeon per 500000 population. $^{3}$ Taking into account the heavy demand of out of hours work $(40 \%$ of paediatric surgery is emergency work) and the consultant led nature of the work, it is suggested that an ideal department should be planned with no fewer than four paediatric surgeons and one paediatric urologist. Thus, 2.5 million will be the minimum population "needed to ensure that there is sufficient critical mass of workload to ensure the clinical viability and effectiveness of a specialised service". ${ }^{7}$ This should mean that a specialist centre should see about 100 new neonatal surgical cases a year and a minimum of 60 cases to remain a viable centre. In addition, neonatal surgery makes use of complex and expensive techniques such as extracorporeal membrane oxygenation, nitric oxide treatment, and high frequency oscillation ventilation, which are best concentrated at a single regional site so that expertise and experience can be gathered by both specialist surgeons and intensivists. Table 1 shows the case load of a typical paediatric surgical centre.

With the rapid advances in antenatal diagnosis babies are no longer referred only at the time of birth, but rather parents are increasingly referred for specialist consultation and counselling from the time of prenatal diagnosis. ${ }^{8}$ Prenatal diagnosis, intervention, and fetal surgery is one of the most complex and controversial areas of medicine today. A multidisciplinary approach, involving paediatric surgeons, fetomaternal physicians, 
Table 1 One year's case load at a typical paediatric surgical centre (Bristol and the South West)

\begin{tabular}{lc}
\hline Population (millions) & 3.3 \\
Number of births (1989) & 41000 \\
Total neonatal surgical admissions & 122 \\
Specialist paediatric surgery & \\
Major neonatal operations & 71 \\
$\quad$ Major non-neonatal operations (excluding & \\
$\quad$ oncology and endoscopy) & 78 \\
Oncology operations (including biopsies) & 59 \\
Insertion of Hickman line & 223 \\
$\quad$ Specialist urology (major cases) & 139 \\
Non-specialist paediatric surgery & \\
$\quad$ Inguinal hernia & 267 \\
$\quad$ Orchidopexy & 131 \\
Pyloric stenosis & 38 \\
\hline
\end{tabular}

ultrasonographers, neonatologists, geneticists, and paediatricians, is essential for diagnosis of the fetus with specific anatomical defects. ${ }^{9}$ It is not difficult to see why some degree of centralisation of service is required with such a large number of specialists needed to make up the team. This not only allows parents to make a rational decision on the outcome of a pregnancy but also, in conjunction with the obstetrician and neonatologist, offers fetal intervention when appropriate, and delivery in the most appropriate setting by the most appropriate route..$^{10-12}$

There are also some adult conditions that specialist paediatric surgeons see infrequently. These are best managed jointly with the specialist adult surgeons; in our unit this specifically refers to thyroid cancer and specialist coloproctology, such as ileo-anal pouches.

\section{ANAESTHESIA}

The 1989 NCEPOD report stated very clearly that anaesthetists should not attempt occasional paediatric practice. ${ }^{213}$ The risks of anaesthesia increase almost 10 -fold in patients under 1 year compared with older children. ${ }^{14}{ }^{15}$ In 1991 Keenan et al found a significant increase in major complications for infants anaesthetised by non-paediatric anaesthetists. ${ }^{16}$ In 1997 Auroy et al showed that groups performing fewer than 100 paediatric anaesthetic procedures a year had a significantly increased complication rate compared with groups performing more than 200 procedures. ${ }^{17}$ Stoddart identified that a major problem of occasional paediatric anaesthetic practice is for the anaesthetist to remain up to date. ${ }^{18}$ There is broad agreement with this general philosophy ${ }^{19}{ }^{20}$; however, it is not happening in practice as shown by the Digivote survey conducted by the Association of Anaesthetists Linkman Conference in 1996-only $60 \%$ of hospitals providing paediatric anaesthesia complied with the Royal College of Anaesthetists' guidelines, ${ }^{21} 22$ and most disturbing of all only $62 \%$ of those present would be happy to allow their own children to be anaesthetised in their own hospital under its current arrangements. ${ }^{20}$

ONCOLOGY

Childhood tumours are biologically different from adult cancers. Based on the finding that survival rates of various cancers greatly improve when treated at centralised specialist centres, ${ }^{23}$ the Chief Medical Officer has recom- mended that all cancer services be centralised and thus coordinated on a regional basis with specified surgeons operating on a required minimum number of cases each year. ${ }^{24}{ }^{25}$ In particular children with cancers such as non-Hodgkin's lymphoma, Ewing's sarcoma, rhabdomyosarcoma, medulloblastoma, and osteosarcoma treated at paediatric oncology centres had a significantly higher survival rate. ${ }^{26}{ }^{27}$ Certain childhood cancers with a good prognosis, such as Wilms's tumour, were being overtreated in non-specialist centres. ${ }^{28}$ The role of the general surgeon in paediatric oncology should be limited to arranging referral to a specialist centre.

\section{TRAUMA}

Traumatic injuries are the most common cause of death in the 1-16 age group. Fundamental anatomical and physiological differences mean that children should not simply be considered as small adults and hence the management of certain injuries differs greatly between children and adults. A good example of this is the nonoperative management of blunt abdominal trauma. In specialist units, proved splenic rupture can be treated either without surgery (in $80-90 \%$ of cases) or with splenic repair in the remainder. ${ }^{29-32}$ Other injuries, such burns ${ }^{33}$ and pelvic fractures, ${ }^{34}$ have also been shown to have different management and outcome in young children. Some investigators claim that childhood trauma is equally well treated by adult surgeons at a level 1 trauma centre, ${ }^{35}{ }^{36}$ while others have found improved outcome for blunt trauma in a designated paediatric trauma centre for the 0 to 11 year age group with significantly reduced rates of liver and splenic resection. ${ }^{32}$ However, all commentators state that if adult trauma surgeons are to treat children they need to develop a special interest in the management of childhood injuries. While it is impractical that all childhood trauma in the UK is managed at regional paediatric surgical centres, there is evidence to suggest that complex trauma has a better outcome with a lower operative morbidity when managed at a specialist unit.

\section{ANCILLIARY SERVICES}

Specialist paediatric surgery depends heavily for support on other specialities such as radiology, pathology, intensive care, physiotherapy, specialist nursing, and nutritionists. Better results for diagnosis and treatment of certain high risk or rare childhood disorders can be achieved by concentrating expertise; this has been shown for radiology, ${ }^{37}$ pathology, ${ }^{38}$ paediatric intensive care, ${ }^{39-42}$ and neonatal intensive care. ${ }^{43}$ In many ways the debate these other specialties have regarding centralisation is remarkably similar; Murdoch and Bihari state that "Paediatric intensive care, to function well, must be associated with a full range of on-site paediatric specialties-cardiology, renal, neurology and surgery." ${ }^{40}$ The forthcoming Troop report is expected to highlight the benefits of carefully planned paediatric intensive care provision, with centralisation of very high intensity level care. Thus specialist techniques and 
expensive equipment, such as high frequency oscillation, nitric oxide treatment, and extracorporeal membrane oxygenation can be evaluated and fairly rationed.

\section{Non-specialist paediatric surgery}

A number of more minor conditions, as defined in the BAPS Guide to Purchasers ${ }^{3}$ are usually treated in district general hospitals. Non-specialist paediatric surgery includes a list of common surgical complaints often dealt with in the district general hospital that do not usually require major operations or perioperative care. These include elective procedures: congenital inguinal hernia, congenital hydrocoele, circumcision, orchidopexy, umbilical hernia repair; and emergency procedures: appendicectomy, correction of torsion of the testis, repair of incarcerated inguinal hernia, and less complex trauma.

\section{UNDESCENDED TESTES \\ "If you people consider the testicle to be a luxury organ to be operated on by non- specialists who am I to complain."-Miss L Kapila, Evidence to the Royal College of Surgeons Working Party}

Studies suggest the rate of orchidopexy nationally may be 2-7 times the incidence of maldescent. ${ }^{44}$ Studies by the Oxford cryptorchidism group ${ }^{45}$ suggest that the operation rates are approximately $2-3$ times the incidence of undescended testis. In addition, inappropriate procedures such as blind exploration of impalpable testes are often carried out ${ }^{46}$ at non-specialist centres.

INGUINAL HERNIA

It may appear that childhood inguinal hernia surgery is relatively straightforward; however, the treatment of neonatal hernias is considered by specialist paediatric surgeons as one of the most technically difficult operations, frequently taking up to two hours to complete. ${ }^{47} 48$ Complications include damage to the vas, testicular vessels, and ultimately infertility. ${ }^{49} 50$

Harper and colleagues ${ }^{51}$ highlighted two avoidable infant deaths, and $\mathrm{NCEPOD}^{2}$ reported five infant deaths from complications related to surgery and anaesthesia after treatment of an inguinal hernia in childhood; all these deaths occurred at non-specialist centres. In addition, there are published data on recurrence rates of $5 \%$ in district general hospitals, which are about double those in specialist units. ${ }^{52} 53$ Taking into account that specialist centres treat far more premature babies, this difference is likely to be even more pronounced.

\section{CIRCUMCISION}

Although male circumcision is a minor surgical procedure, it is associated with numerous complications $^{54}$ including haemorrhage, ${ }^{55}$ meatal stenosis, ${ }^{56}$ and long term psychological trauma. ${ }^{54}{ }^{57}$ Unless the surgeon is knowledgeable about the natural history of foreskin problems and experienced in their management, up to two thirds of operations will be performed unnecessarily ${ }^{58-60}$; this suggests more than 13000 unnecessary circumcisions may be performed annually in the UK.

INTUSSUSCEPTION

Avoidable deaths still occur from intussusception. Stringer et al in 1992 showed that while some deaths were caused by delayed diagnosis and late referral to hospital, $60 \%$ are related to mismanagement in hospital. ${ }^{61}$ Of the patients who died in hospital only one was under the care of a specialist paediatric surgeon and he had undergone laparotomy at another district general hospital. Morbidity also occurs from avoidable laparotomy. ${ }^{62}$ More than $80 \%$ of intussusceptions can be reduced using air or barium enema ${ }^{37}{ }^{63}$ when attempted by an experienced paediatric radiologist. This contrasts with the most recently reported study of intussusception from a district general hospital of a $44 \%$ resection rate of all intussusceptions. ${ }^{64}$

INFANTILE HYPERTROPHIC PYLORIC STENOSIS

The incidence of pyloric stenosis is around 3-4 per 1000 live births ${ }^{65}{ }^{66}$ Thus an average district general hospital (200 000 population and 2300 live births ${ }^{67}$ ) should see around 6-10 cases of pyloric stenosis each year. The question of who should treat pyloric stenosis is hotly debated. Although one paper has shown good results from a district general hospital, ${ }^{68}$ other reports have shown mucosal perforation rates and wound infection rates twice that of specialist centres and a wound failure rate five times those achieved within specialist centres. ${ }^{69} 70$ When the surgical care of all children at a district general hospital was transferred from general surgeons to a trained paediatric surgeon at the same hospital the complication rate fell from $33 \%$ to almost nil. ${ }^{71}$

\section{Training}

The combination of a shortened training period $^{72}$ and the "new deal" on junior doctors" hours ${ }^{73}$ has serious implications for training. ${ }^{74} 75$

Formerly training in paediatric surgery involved training in general surgery followed by training in paediatric surgery. Most neonatal surgical conditions are complex and rare; congenital diaphragmatic hernia, 1 in 2000 live births; tracheoesophageal fistulas, 1 in 4000 live births; Hirschsprung's disease, 1 in 5000 live births. This means that either large numbers of cases need to be concentrated in one centre or training time needs to be increased (by increasing on call commitment or length of training) if we are going to achieve the case mix that is considered essential for a specialist paediatric surgeon. ${ }^{76}$ Large specialist centres allow concentration of cases that can support a minimum of five consultant paediatric surgeons and thus provide adequate training. However, the formation of NHS trusts has meant an end to regional planning and hence Trust Hospitals can set up small paediatric surgical units and appoint who they wish without regard to the national picture - as the Chief Medical Officer is aware. ${ }^{77}$ 
Training is also highlighted as a problem in other allied specialities such as paediatric intensive care $^{40}$ and anaesthesia. ${ }^{18}$

A separate issue is the training of general surgeons and anaesthetists performing nonspecialist surgery in district general hospitals. As we have highlighted there are significant differences in the reported results of treatment of non-specialist paediatric surgical conditions. NCEPOD 1989 reported that $24 \%$ of surgeons who operated on children aged 3-10 years did fewer than 20 such operations each year, and $83 \%$ operated on fewer than 20 patients who were younger than 6 months. Despite over 84000 general paediatric surgical cases being dealt with in district general hospitals in $1994-95^{78}$ only 36 general surgeons (3\%) declared it as a sub-specialty interest in a questionnaire on specialisation in general surgery. ${ }^{79}$ In 1992 the joint committee on higher surgical training's specialist advisory committees in general and paediatric surgery agreed that general surgeons intending to undertake paediatric practice should spend at least six months training in a specialist paediatric surgical centre ${ }^{80}$ NECPOD advised that children's surgery in the district general hospital should be under the care of named surgeons and anaesthetists with an interest in paediatric surgery ${ }^{2}$ so that occasional paediatric practice becomes a thing of the past. ${ }^{13} 20$

\section{Summary}

We have tried to review the evidence for the organisation of paediatric surgical care. Difficulties arise because of the lack of published data from district general hospitals concerning paediatric surgical conditions. Hence much of the debate about the surgical management of children is based on anecdotal evidence. However, at a time when the provision of health care is being radically reorganised to an internal market based on a system of purchasers and providers it is more important than ever to understand the issues at stake. Two separate issues have been discussed: the role of the specialist paediatric centre and the provision of non-specialist paediatric surgery in district general hospitals.

There are arguments for and against large regional specialist paediatric centres. The benefits of centralisation include concentration of expertise, more appropriate consultant on call commitment, development of support services, and junior doctor training. The disadvantages include children and their families having to travel long distances for care, and the loss of expertise at a local level. If specialist paediatric emergency transport is available the benefits of centralisation far outweigh the adverse effects of having to take children to a regional paediatric intensive care centre. ${ }^{21}{ }^{42}$ Specialist paediatric centres are aware of the importance of treating children and their parents as a family unit as highlighted by the Platt committee ${ }^{1}$; this is an important challenge and enormous improvements have occurred to provide proper accommodation for families while their children are treated in hospital. To keep these arguments of large distances and separation from the home in context, one paediatric intensive care unit in Victoria, Australia, providing a centralised service to a region larger in area than England and with a similar admission rate, has a lower mortality rate than the decentralised paediatric intensive care provided in the Trent region of the UK. ${ }^{42}$

There is clear evidence that all neonatal surgery and anaesthesia should be conducted only by specialists. ${ }^{46}$ The debate now centres around the number of complex surgical cases a unit should treat to maintain its specialist status. The NHS executive, in its guidelines on contracting for specialist services, emphasises that "Sensible contracting needs to take into account the optimum population size not only for the stability of contracted referrals but also to give sufficient 'critical mass' for clinical effectiveness." Achieving this balance has consequences, not just for the maintenance of surgical expertise, but for the essential ancilliary services. There is clear evidence in anaesthesia that anaesthetists doing small numbers of neonatal procedures had significantly worse results. $^{2}{ }^{13}{ }^{16-18}$ The same seems to be true in the fields of oncology, ${ }^{26}{ }^{27}$ radiology, ${ }^{37}$ pathology, ${ }^{38}$ and intensive care. ${ }^{39-41} 43$

The reasons why the results of management of certain paediatric conditions are better at specialist centres are open to speculation. Presumably greater exposure to rare complex cases, concentration of expertise, more peer review, and a trickle down effect of the multidisciplinary approach all help to keep health care workers up to date with current world practice. In addition, it allows for appropriate specialist on call rotas and dedicated junior staff. If insufficient numbers of specialist surgical cases are being treated at a centre then the whole multidisciplinary team suffers. The 1989 NCEPOD report states "that paediatricians and general surgeons must recognise that small babies differ from other patients not only in size, and that they pose quite separate problems of pathology and management." ${ }^{2}$ The need for large centres of paediatric surgical expertise is now accepted by the Royal College of Surgeons of England, ${ }^{80}$ the British Association of Paediatric Surgeons, ${ }^{381}$ the Senate of Surgery of Great Britain and Ireland, ${ }^{78}$ the Royal College of Paediatrics and Child Health, ${ }^{21}$ the Royal College of Anaesthetists, ${ }^{22}$ the Audit Commission, ${ }^{82}$ and the Chief Medical Officer. ${ }^{77} 83$

The other point of debate is the role of district general hospitals providing a paediatric surgical service. Brain and Roberts have shown the benefits of a properly trained paediatric surgeon taking over the children's surgery at a district general hospital. ${ }^{71}$ All commentators regardless of specialty or place of work (large specialist surgical centre or district general hospital) are united in their belief that occasional paediatric practice is a thing of the past. ${ }^{192135828485}$ Furthermore, if surgeons and anaesthetists are to maintain a paediatric practice in a non-specialist centre, they have a duty to train appropriately, maintain their practice in line with current guidelines, and make sure 
that other members of the multidisciplinary team do the same.

The aims of the specialist centre and the district hospital are essentially the same- to treat patients efficiently with a consistently high level of care. The hub and spoke model described by Rollin ${ }^{20}$ has much to commend it. The aim would be a limited number of specialist centres, each surrounded by centres of competence serving local communities. For this to be achieved in line with the recommendations of the Platt report ${ }^{1}$ both types of hospital must recognise that they have aims in common and skills that are complementary. They can then work together to provide the facilities and expertise that is demanded of a children's surgical service at both local and regional level.

1 Report of the Platt committee. The welfare of children in hospital. London: HMSO, 1959.

2 National enquiry into perioperative deaths. London: NECPOD, 1989

3 British Association of Paediatric Surgeons. A guide for purchasers and providers of paediatric surgical services. Edinburgh: The Royal College of Surgeons of Edinburgh, 1995.

4 Hendren HW, Lillehei CW. Pediatric surgery. $N$ Engl f Med 1988;319:86-95.

5 Stringer MD, Bereton RJ, Wright VM. Controversies in the management of gastroschisis: a study in 40 patients. Arch management of gastroschis $1991 ; 66: 34-6$.

6 Spitz L. Neonatal surgery. F R Coll Surg Edinb 1995;40:84-

7 NHS Management Executive. Contracting for specialist services. London: Health Publications Unit, 1993.

8 Rice HE, Adzick NS. Prenatal diagnosis: essentials for the pediatric surgeon. Semin Pediatr Surg 1993;2:84-91.

9 Wilkinson LG, Powell RW, Cabaniss ML, et al. Surgical problems in the fetus: a multidisciplinary approach. Am $\mathcal{F}$ Surg 1987;154:685-7.

10 Harrison MR, Adzick NS, Flake AW. Congenital diaphragmatic hernia: an unsolved problem. Sem Pediatr Surg 1993; 2:109-12.

11 Crombleholme TM, D'Alton M, Alman B, et al. Prenatal diagnosis and the pediatric surgeon: the impact of prenatal consultation on

12 Adzick NS, Harrison MR. Fetal surgical therapy. Lancet 1994;343:897-902.

13 Lunn JN. Implications of the national confidential enquiry into perioperative deaths for paediatric anesthesia. Paediat Anaesth 1992;2:69-72.

14 Tiret L, Nivoche Y, Hatton F, Desmonts JM, Vourac'h G Complications related to anaesthesia in infants and children. Br F Anaesth 1988;61:263-9.

15 Cohen MM, Comeron CB, Duncan PG. Pediatric anesthesia morbidity and mortality in the perioperative period. Anesth Analeg 1990;70:160-7.

16 Keenan RL, Shapiro JH, Dawson K. Frequency of anesthetic cardiac arrests in infants: effect of pediatric anesthetic cardiac arrests in infants: effect of pediatric anesthesio.

17 Auroy Y, Ecoffey C, Messiah A, Rouvier B. Relationship between complications of pediatric anesthesia and voulme of pediatric anesthetics. Anesth Analg 1997;84:228-36.

18 Stoddart PA, Brennan L, Hatch DJ, Bingham R. Postal survey of paediatric practice and training among consultan anaesthetists in the UK. Brf Anaesth 1994;73:559-63.

19 McNicol R. Paediatric anaesthesia-who should do it? The view from the specialist hospital. Anaesthesia 1997;52:51316.

20 Rollin EM. Paediatric anaesthesia-who should do it? The view from the district general hospital. Anaesthesia 1997;52:513-16.

21 Report of the Working Party. The transfer of infants and children for surgery. London: British Association of children for surger

22 Guidance for purchasers of paediatric anaesthesia. London: Royal College of Anaesthetists, 1994

23 Stiller CA. Centralised treatment, entry to trials and survival. Br f Cancer 1994;70:352-62.

24 Chief Medical Officer's expert advisory group on cancer. $A$ policy framework for commissioning cancer services. London Department of Health, 1995

25 NHS executive. Improving outcomes in breast cancer: guidance for purchasers. London: Health Publications Unit, 1996.

26 Stiller CA. Centralisation of treatment and survival rates for cancer. Arch Dis Child 1988;63:23-30.

27 Danjoux CE. Childhood medulloblastoma in Ontario, 1977-87: population based results. Med Pediatr Onco 1996;26:1-9.

28 Pritchard J, Stiller CA, Lennox EL. Overtreatment of children with Wilms's tumour outside paediatric oncology centres. BMF 1989;299:835-6.
29 Douglas GJ, Simpson JS. The conservative management of splenic trauma. $\mathcal{F}$ Paediatr Surg 1971;6:565-8.

30 Haller JA. Emergency medical services for children: what is the pediatric surgeon's role? Pediatrics 1987;79:576-80.

31 Yoo SJ, Lim KS, Kang SJ, Kim CS. Pitfalls of non-operative management of blunt abdominal trauma in chidren in Korea. F Paediatr Surg 1996;31:263-6.

32 Hall JR, Reyes MR, Meller JL, Loeff DS, Dembek R. The outcome for children with blunt trauma is best at a pediatric trauma centre. F Paediatr Surg 1996;31:72-7.

33 Morrow SE, Smith DL, Cairns BA, et al. Etiology and outcome of pediatric burns. F Paediatr Surg 1996;31:329-33.

34 Ismail N, Bellemare JF, Mollitt DL, et al. Death from pevic fracture: chidren are different. F Paediatr Surg 1996;31:82-

35 Knudson MM, Shagoury C, Lewis FR. Can adult trauma surgeons care for injured children? F Trauma 1992;32:72937.

36 Fortune JB, Sanchez J, Graca L. A paediatric trauma center without a pediatric surgeon: a four year outcome analysis. $\mathcal{F}$ Trauma 1992;33:130-9.

37 Ein SH, Palder SB, Alton DJ, Daneman A. Intussception: toward less surgery? F Paediatr Surg 1994;29:433-5.

38 Parkes SE, Muir KR, Cameron AH, et al. The need for specialist review of pathology in paediatric cancer. $\mathrm{Br} \mathcal{F}$ Cancer 1997;75:1156-9.

39 Shann F. Australian view of paediatric intensive care in Britain [letter]. Lancet 1993;342:68.

40 Murdoch IA, Bihari DJ. Paediatric and adult intensive care in Britain [letter]. Lancet 1993;342:498.

41 Tibby S, Hatherill M, Marsh MJ, Murdoch IA. Paediatric intensive care beds: the problem is distribution rather than numbers [letter]. BMF 1996;312:773.

42 Pearson G, Shann F, Barry P, et al. Should paediatric intensive care be centralised? Trent versus Victoria. Lancet 1997;349:1213-17.

43 Field D, Hodges S, Mason E, Burton P. Survival and place of treatment sfter preterm delivery. Arch Dis Child 1992;66: $408-11$

44 Steeno O, Van Ferven V, Knops J. The increase in number of orchidopexies: rather cause than prevetion of male infertility. Andrologia 1988;20:502-6.

45 John Radcliffe Hospital Cryptorchidism Group. Cryptorchidism: an apparent substantial increase since 1960. BMF 1986;293:1401-4.

46 Lakhoo K, Thomas DFM. Is inguinal exploration for the impalpable testis an outdated operation? $\mathrm{Br} \mathcal{F}$ Urol 1996;77:452-4.

47 Groff DB, Nagaraj HS, Pietsch JB. Inguinal hernias in premature infants operated on before discharge from the neonatal intensive care unit. Arch Surg 1985;120:962-3.

48 Rajput A, Gauderer MWL, Hack M. Inguinal hernias in very low birthweight infants: incidence and timing of repair. F Paediatr Surg 1992;27:1322-4.

49 Walc L, Bass J, Rubin S, Walton M. Testicular fate after incarcerated hernia repair and/or orchiopexy performed in patients under 6 months of age. F Paediatr Surg 1995;30: $1195-7$

50 Matsuda T, Hiura Y, Muguruma K, et al. Quantitative analysis of testicular histology in patients with vas deferens obstruction caused by childhood inguinal herniorrhaphy: comparison to vasectomized men. $\mathcal{F}$ Urol 1996;155:564-7. 1 Harper SJ, Bush GH. Deaths in children with inguinal hernia [letter]. $B M 7$ 1988;296:210

52 Fung A, Barsoum G, Bentley TM, Wild K, Klikjian AM. Inguinal herniotomy in young infants. Br f Surg 1992;79: 1071-2.

53 Tam PK, Tsang TM, Saing H. Inguinal hernia in Chinese children. Aust NZ F Surg 1988; 58:403-6.

54 Williams N, Kapila L. Complications of circumcision. $\mathrm{Br} \mathcal{F}$ Surg 1993;80:1231-6.

55 Tsang TM, Tam PKH. Complications of circumcision. $\mathrm{Br} \mathcal{F}$ Surg 1994;81:470-5.

56 Persad R, Sharma S, McTavish J, Imber C, Mouriquand PDE. Clinical presentation and pathophysiology of meatal stenosis following circumcision. Br F Urol 1995;75:91-3.

57 Taddio A, Katz J, Ilersich AL. Koren G. Effect of neonatal circumcision on pain response during subsequent routine vaccination. Lancet 1997;349:599-603.

58 Williams N, Chell J, Kapila L. Why are children referred for circumcision [letter]? BMf 1993;306:28.

59 Griffiths D, Frank JD. Inappropriate circumcision referrals by GP's. F $R$ Soc Med 1992;85:324-5.

60 Rickwood AMK, Waker J. Is phimosis overdiagnosed in boys and are too many circumcisions performed in consequence? Ann R Coll Surg Engl 1989;71:275-7.

61 Stringer MD, Pledger G, Drake DP. Childhood deaths from intussusception. BM7 1992;304:737-9.

62 den Hollander D, Burge DM. Exclusion criteria and outcome in pressure reduction of intussusception [see comments]. Arch Dis Child 1993;68:79-81.

63 Stringer MD, Pablo SM, Brereton RJ. Paediatric intussusception. Br F Surg 1992;79:867-76

64 Thomas DF. The management of childhood intussusception in a district hospital. Br f Surg 1980;67:33-5.

65 Spicer RD. Infantile hypertrophic pyloric stenosis: a review. Br F Surg 1982;69:128-35.

66 Pemberton PJ. Organization of a neonatal surgical unit. In: Freeman NV, Burge DM, Griffiths DM, Malone PSJ, eds. Surgery of the newborn. Edinburgh: Churchill Livingstone, 1994:-3-9.

67 Office for National Statistics. Livebirths and perinatal mortality rates 1996. London: Monitor Population and Health, 1997. 
68 Saunders. Infantile hypertrophic pyloric stenosis: experience in a district general hospital. $\mathcal{F} R$ Coll Surg Edinb 1990;35:36-8.

69 McDonald PJ. Ramstedt's operation in district general hospitals - is it safe? F R Soc Med 1986;79:17-18.

70 Benynon J, Brown R, James C, Fernando R. Pyloromyotomy: can the morbidity be improved. $f \mathrm{R} \mathrm{Coll}$ Surg Edinb 1987;32:291-2.

71 Brain AJL, Roberts DL. Who should treat pyloric stenosis: the general surgeon or specialist paediatric surgeon? $\mathrm{F} \mathrm{Pae}$ diatr Surg 1996;31:1535-7.

72 Report of the Working Group on Specialist Medical Training. Hospital doctors: training for the future. London: Department of Health, 1993.

73 Hours of work of doctors in training: the new deal. London: Department of Health, 1991.

74 Biggs J. New arrangements for specialist training in Britain. BMF 1995;311:1242-3.

75 Wong C. Members of junior doctors committee are in cloud cuckoo land [letter]. BMF 1995;311:632.

76 Spitz L. So you want to train in paediatric surgery. Br f Hosp Med 1996;56:281-3.

77 Chief Medical Officer. Report on British Association of Paediatric Surgeons meeting with Dr Kenneth Calman. Provision of paediatric surgical services. London: Department of Health, 1995.

78 The Senate of Surgery of Great Britain and Ireland. Report of the working party on the provision of general surgical services for children. The Senate of Surgery of Great Britain and Ireland, 1997. [In press.]

79 Watkin DFL, Jackson BT. Specialisation within general surgery. 75th Anniversary Year Book. Association of Surgeons of Great Britain and Ireland. Middlesex: The Rowan Group, 1995:25-7.

80 Commission on the Provision of Surgical Services. Report of the working party on surgical services for the newborn. London: Royal College of Surgeons of England, 1992.

81 Submission from British Association of Paediatric Surgeons. House of Commons Inquiry into Children's Health. House House of Commons Inquiry into Children's Health. House
of Commons Select Committee on Health. Health Services of Commons Select Committee on Health. Health Services
of Children and Young People. 128ii, Session 1996-97:4873 .

83 Audit Commission. Children first: A study of hospital services. London: HMSO, 1993.

84 Senior Medical Officer. Meeting of BAPS Executive with Dr McGovern. Paediatric Surgical Centres. London Department of Health, 1996.

85 Jones PF. The general surgeon who cares for children. BMf 1986;293:1156-8.

86 Atwell JD, Spargo PM. The provision of safe surgery for children. Arch Dis Child 1992;67:345-9.

\section{Commentary}

I was very interested to read Arul and Spicer's review. It goes without saying that their conclusions are heavily in favour of more paediatric surgery being done in specialist centres, and they muster several good arguments and reviews in their favour. However, the object of my commentary is to be provocative-I will try to be just that.

There is much logic in Arul and Spicer's analysis that there is plenty of room for improvement of paediatric surgical services in district general hospitals. Better training (basic, advanced, and continuing medical education $(\mathrm{CME}))$ for all those practising paediatric surgery, anaesthesia, and nursing must be available, and without question the recommendations of the Platt report and NCEPOD must be fully implemented if we are to bring children's surgery in the UK up to standard.

I agree that no-one can take issue with the proposal that neonatal surgery should be carried out in regional centres, or that surgeons and anaesthetists who operate only occasionally on children should be discouraged from doing so. Without doubt there are district general hospitals up and down the country who have failed to designate a paediatric surgeon and an anaesthetist to specifically support the local paediatricians and still have several surgeons all "doing a bit".

However, the evidence that non-specialised paediatric elective surgery (for example, groin surgery) and relatively common paediatric emergencies (for example, appendicectomy, intussusception, and hypertrophic pyloric stenosis) fare much worse in district general hospitals is weak in the extreme. Although I am flattered that Arul and Spicer have quoted my most modest contribution to the literature of this subject, they have represented my careful audit of Ramstedt's operation as showing poorer results than expected from a specialist centre. In fact, my conclusion was quite the opposite. The results were probably as good as the regional centre in which I later worked, although at that time I was not able to analyse those precisely.

All this makes me think that we generalists are far from throwing in the towel and abandoning all those paediatricians who do not have the fortune of being in a specialist surgery hospital. Instead I would argue that the literature does not support sending all those patients to the regional centres. Arul and Spicer acknowledge that 84000 paediatric surgical cases were dealt with in district general hospitals in 1994; to move these to regional or subregional centres might be beyond the wit of the NHS for a while to come and I think would greatly be to the detriment of children's relatives.

Of course, the great flaw of Arul and Spicer's advocacy of centralising all paediatric general surgical services is that there will still be an enormous number of children treated by nonpaediatric orientated surgeons in otolaryngology, orthopaedics, and neurosurgical units all over the country. There is no suggestion that paediatric surgeons take over otorhinolaryngological cases or the treatment of congenital dislocation of the hips. After all, paediatric surgeons already have enough on their plates (chest, urology, coloproctology, gastroenterology, and plastic surgery). Sometimes adult surgeons who specialise in about 10 operations each (now mostly confined to one area of the body) wonder how paediatric surgeons can keep their skill levels up on so few cases!

How are we to proceed now that the Calman training problem is besieging us? Do we see paediatric surgery breaking away from general surgery completely as urology has in the past 20 years? That will mean that every district general hospital (soon all to have a catchment population of 500 000) will need one or two dedicated paediatric surgeons. If these doctors operate only on children they will want to do the complex neonatal surgery as well because the intellectual stimulus of non-specialist paediatric surgery is so limited. Yet a catchment population of 500000 will not be enough to supply these surgeons with adequate neonatal surgery to keep their skills up. The paradox might be that the bread and butter work might be done better while the rarer neonatal surgery will suffer.

The sensible alternative is that general surgeons with an interest in paediatric surgery take on the basic work, organise the service, and refer on the difficult cases to their contacts in the regional children's hospitals. The specialist paediatric surgeons who now supply a network of peripatetic outpatient services will naturally still be part of this model. 
It is within the ingenuity of BAPS to specify which operations could be done by such general surgeons with an interest, and it should also be possible for the same organisation to provide adequate training (one year with CME to follow) for these individuals. In this way Rollin's hub and spoke arrangement could be made to work.

Finally, although Dennis Browne may have said that setting a standard is not to create a monopoly there is a creeping feeling in all this that there may be a grain of a lie in these fine words. Of this we must be aware if we are going to continue to improve the service for our patients, their relatives, and our paediatrician colleagues.

PETER MCDONALD Consultant Surgeon, Northwick Park and St Mark's Hospitals, Watford Road, Harrow, Middlesex HA1 3UF, UK

\section{Commentary}

The vexing questions of who? and where? in matters pertaining to paediatric (especially neonatal) anaesthesia is fuelled by Arul and Spicer in this paper. They promote specialist centre anaesthesia and support the ideal of specialist surgical centres. This ideal is likely to remain far from reality, although most anaesthetists, especially non-designated paediatric anaesthetists, would like it to be implemented. No-one working in the district general hospital environment could disagree with the statement that experience, equipment, staffing, anaesthetic assistance, and recovery facilities are not as good as those in a specialist unit. These are issues that all paediatric district general hospital anaesthetists grapple with daily. There are not enough trained paediatric anaesthetists maintaining CME to facilitate a continual daily rota and on call cover in most hospitals.

This leads to many difficulties in managing paediatrics in district general hospitals. They now try to concentrate a major proportion of the paediatric services on a designated anaesthetist. This has certain advantages including an educated, experienced anaesthetist, a commitment to trainee teaching, and responsibility for the maintenance of standards and equipment. However it does further diminish the capabilities of the non-specialist anaesthetist who will have to anaesthetise neonates at some time, even if only when the paediatric anaesthetist is away from the hospital. There will be occasions-after trauma or in a surgical or medical emergency - when the sickest child will be looked after by an inexperienced paediatric anaesthetist. There will always be emergencies to deal with. The most obvious and now thankfully less common emergency is that of bypassing the obstructed upper airway in acute epiglottitis. This is reality, but it does not imply that the casual paediatric anaesthetist is doing a poor job at managing difficult situations. It must be remembered that all consultant anaesthetists have been trained in paediatric anaesthesia.

How bad are the paediatric anaesthetic services in district general hospitals? NCEPOD 89 is really the only reference source and it contains few data to support its recommendations. Despite a few cases of concern the standard of anaesthesia was perceived as generally excellent. ${ }^{1}$ In the report there is no reference to avoidable deaths from anaesthesia and of the five cases of concern possibly only one would have been handled differently if the recommended changes had been implemented - two would still have been handled as district general hospital emergencies by non-specialist anaesthetists. ${ }^{2}$

Atwell and Spargo ${ }^{3}$ state that "there are no data comparing paediatric anaesthetic morbidity in the DGH with that in the regional paediatric unit" and when talking about the complications of operations comparing the district general hospital with the specialist unit it is important to remember that surgical deaths should not be equated with anaesthetic deaths. This may appear to be a pedantic statement and it must be conceded that often the anaesthetist must carry as much responsibility as the surgeon when there is a death in a hospital that lacks the infrastructure to care for the child.

This is such a topical and pertinent issue yet one is tempted to ask why there are no data other than NCEPOD 89, and why there has not been any re-analysis of these data. There appears to be no other data to support or contradict this audit report.

Why has NCEPOD 89 not been implemented? The specialist unit could not cope with the sheer volume of paediatric work that is available. The infrastructure does not exist and many problems would be difficult to manage. These include distances of travel, interhospital transfer hazards for the patient, and disruption for the patient's family. Additionally, the specialist centre, which is often overstretched, may not be able to cope and super-specialists skills may be unfulfilled.

The problem is difficult to resolve and requires responsible management by those in district general hospitals. If the surgeon or the anaesthetist is not confident of their own or the hospital's ability to manage a difficult case, surely common sense should prevail and transfer to a specialist centre be mandatory. Normally anaesthetists are realistic about their inabilities in difficult circumstances and most are reluctant, even at a senior consultant level, to endanger life when they are not confident.

One of the obvious problems that can be addressed is where to site a regional specialist paediatric centre? Is there still a place for isolated specialist paediatric units in medicine and surgery as we approach the millennium? Many opinions prevail and any solutions must be made solely in the interests of safe paediatric practice-perhaps they should be a satellite attached to a major district general hospital. This concept has already been shown to work successfully and may be the way forward.

P N ROBINSON Consultant Anaesthetist Northwick Park Hospital, Watford Road, Harrow, Middlesex HA1 3UF, UK 
1 Campling EA, Devlin HB, Lunn JN. The report of the national confidential enquiry into perioperative deaths.

2 Heneghan C, Harrison C. Paediatric anaesthesia-who should do it? Anaesthesia 1998;53:201-2.

3 Atwell JD, Spargo PM. The provision of safe surgery in children. Arch Dis Child 1992;67:345-9.

\section{Commentary}

The concentration of paediatric surgery in designated centres serving a population of around 2.5 million is an established principle of BAPS. ${ }^{1}$ Until recently, it was advocated that the recommended staffing complement of each unit should be five paediatric surgeons, one of whom should specialise in paediatric urology. With the advent of the Calman training scheme and the desire to implement an enhanced consultant based service, it will clearly be necessary in the immediate future to increase the staffing levels in these units. The concentration of clinical material in designated centres should, as Arul and Spicer indicate, bring about an improvement in the results achieved. In addition, the expertise of the consultants will be enhanced, research and development will be advanced, and the training of future generations of paediatric surgeons ensured. It is only in such centres that the whole range of ancillary services-anaesthesia, intensive care, registered children's nurses, radiology, pathology, and the full complement of allied surgical and medical services-can be concentrated all working together to improve the outcome for the child.

Neonatal surgery has undeniably become the monopoly of the paediatric surgeon. The need for other conditions, such as solid tumours, complex gastrointestinal or urogenital anomalies, hepatobiliary disorders, and major trauma to be managed in designated centres is also generally accepted. Children with relatively minor surgical problems who have an associated medical or surgical condition may require the expertise available only in these centres.

It is clear that paediatric surgeons cannot currently assume control of all surgical conditions in children. There is, therefore, a previously unfulfilled need to train general surgeons in district general hospitals to carry out surgery in the older infant and child. The Senate of the Royal Colleges of Surgeons has recommended that general surgeons undertaking the care of paediatric surgical patients in district general hospitals should have undergone a six month period of training in an approved paediatric surgical unit in year 3 of training or above. In addition, these "general paediatric surgeons" should participate in audit, and maintain continuing education in paediatric surgery. ${ }^{2}$
Examples of conditions that clearly should fall within the expertise of the "general paediatric surgeon" are elective procedures such as inguinal and umbilical herniotomy, orchidopexy, and circumcision, and emergency operations for acute appendicitis, intussusception, and pyloric stenosis. With reference to intussusception the success rate for air or hydrostatic reduction is greatly improved when the procedure is carried out by an experienced paediatric radiologist. Mortality in intussusception is almost universally caused by mismanagement of fluid and electrolyte homeostasis. ${ }^{3}$ Surgical intervention in intussusception and pyloric stenosis will be entirely dependent on the availability of an anaesthetist trained in paediatrics. Infants and young children with appendicitis frequently present with perforation and require meticulous resuscitation before surgery to avoid unnecessary mortality and morbidity. ${ }^{4}$ Knowledge of the fluid and electrolyte requirements of the paediatric patient is thus mandatory for the "general paediatric surgeon".

A total of 32674 circumcisions were carried out in NHS hospitals in England during the year 1995-96. If, as suggested, two thirds of these procedures were not medically indicated, ${ }^{5}$ more than 21000 unnecessary circumcisions were performed consuming substantial resources. A clear understanding of the natural history of the foreskin would result in a significant reduction in the number of circumcisions performed.

Similarly, the number of orchidopexies exceeds the incidence of maldescent by a factor of 2-7. A carefully conducted clinical examination will eliminate the retractile testis that is destined to descend spontaneously and for which orchidopexy is totally unnecessary. Arul and Spicer have shown the obvious advantages of concentrating paediatric surgery into designated units. There remains a clear need to train the general surgeon in defined aspects of paediatric surgery so that these patients can be safely managed in district general hospitals.

LEWIS SPITZ Nuffield Professor of Paediatric Surgery, Institute of Child Health, 30 Guilford Street, London WC1N 1EH, UK

1 A guide for purchasers and providers of paediatric surgical servces. London: British Association of Paediatric Surgeons, 1995.

2 Report of the working party on the provision of general surgical services for children. Senate of Surgery of Great Britain and Ireland, 1997.

3 Stringer MD, Pledger G, Drake DP. Childhood deaths from intussusception-England and Wales 1984-9. BMF 1992; intussuscep

4 Pledger HG, Fahy LT, van Mourik, GA, Bush GH. Deaths in children with a diagnosis of acute appendicitis in England and Wales 1980-4. BMF 1987;295:1233-5.

5 Rickwood AMK, Walker J. Is phimosis overdiagnosed in boys and are too many circumcisions performed in consequence? Ann R Coll Surg Engl 1989;71:275-7. 